\title{
Correction to: Femoral insertion site of the graft used to replace the medial patellofemoral ligament influences the ligament dynamic changes during knee flexion and the clinical outcome
}

\author{
Vicente Sanchis-Alfonso ${ }^{1,2} \cdot$ Cristina Ramirez-Fuentes $^{3} \cdot$ Erik Montesinos-Berry $^{4,5} \cdot$ Julio Domenech $^{2}$. \\ Luis Martí-Bonmatí ${ }^{3}$
}

Published online: 2 November 2018

(c) European Society of Sports Traumatology, Knee Surgery, Arthroscopy (ESSKA) 2018

\section{Correction to: Knee Surg Sports Traumatol Arthrosc https://doi.org/10.1007/s00167-015-3905-0}

Unfortunately, the author missed out to indicate the affiliation which is basic requirement as a part of his thesis. The affiliation is now updated here.

The original article can be found online at https://doi.org/10.1007/ s00167-015-3905-0.

Vicente Sanchis-Alfonso

vicente.sanchis.alfonso@gmail.com

1 Hospital 9 de Octubre, Valencia, Spain

2 Hospital Arnau de Vilanova, Valencia, Spain

3 Department of Radiology, Hospital Universitario y Politécnico La Fe and GIBI230 IIS La Fe Research Group, Valencia, Spain

4 Agoriaz Orthopedic Center, Riaz, Switzerland

5 Universidad Autonoma de Barcelona (UAB), Bellaterra, Spain 